\title{
Prevalence, Factors, and Outcome of Physical Violence against Mental Health Professionals at a Nigerian Psychiatric Hospital
}

\author{
OO Akanni, AF Osundina, SO Olotu, IO Agbonile, AN Otakpor, AL Fela-Thomas
}

\begin{abstract}
Objectives: This cross-sectional study aimed to assess the prevalence, factors, and consequences of physical violence by mentally ill patients against mental health professionals.

Methods: 124 of 145 mental health professionals at a Nigerian neuropsychiatric hospital satisfactorily completed a questionnaire on their experiences with physical assault.

Results: $77(62.1 \%)$ staff had been assaulted during their whole career; $38(30.6 \%)$ of them were assaulted in the past 12 months. The most common type of assault was pushing (32.9\%). The most common antecedent event to assault was calming an aggressive patient (44.1\%). In their whole career, $22.1 \%$ of assaulted staff sustained injuries that required medical attention; $42.4 \%$ of assaulted staff sometimes or frequently/always experienced posttraumatic stress disorder symptoms. Physical assault in the whole career was associated with older age $(p=0.04)$, longer years of practice $(p=0.01)$, and job dissatisfaction $(\mathrm{p}=0.05)$.

Conclusions: Physical violence encountered by mental health professionals at a Nigerian neuropsychiatric hospital is substantial. Policy review of staff safety, training, and support is recommended.
\end{abstract}

Key words: Job satisfaction; Mentally ill persons; Nigeria; Physical abuse

Oluyemi O Akanni, FWACP, FMCPsych, Federal Neuropsychiatric Hospital, Benin, Edo, Nigeria

Adeagbo F Osundina, FWACP, Federal Neuropsychiatric Hospital, Benin, Edo, Nigeria

Sunday O Olotu, FWACP, Federal Neuropsychiatric Hospital, Benin, Edo, Nigeria

Imafidon O Agbonile, MPh, FWACP, Federal Neuropsychiatric Hospital, Benin, Edo, Nigeria

Alex N Otakpor, BCBA-D (US), FWACP, FMCPsych, Department of Mental Health, University of Benin Teaching Hospital, Benin, Edo, Nigeria

Ayodele L Fela-Thomas, MSc, FWACP, FMCPsych, Federal Neuropsychiatric Hospital, Benin, Edo, Nigeria

Address for correspondence: Dr Oluyemi O Akanni, Federal Neuropsychiatric Hospital,Benin, Edo, Nigeria.Email: poppaul2002@gmail.com

Submitted: 1 August 2017; Accepted: 7 May 2018

\section{Introduction}

Workplace violence in the form of physical or verbal attacks against health care personnel is common. ${ }^{1,2}$ It may be mindless, random, or gratuitous act perpetrated by colleagues, staff, employers, patients/clients, or visitors to a treatment facility. ${ }^{3}$ It is especially disturbing when the physical attack is perpetrated by care-recipients on caregivers. Such violence and its sequelae have been reported in mental health treatment facilities. ${ }^{4-8}$

Mental health caregivers are exposed to a $>50 \%$ risk of being physically assaulted by a patient during their whole career. ${ }^{5}$ This estimate is greatly determined by the type of job of the mental health professional, the type of illness of the patient, the severity of illness, and environmental or situational factors. For example, patients with schizophrenia, bipolar disorder, or major depression are two to three times more likely to be assaultive than people without such illnesses. ${ }^{9}$ Nursing staff are at a higher risk than other mental health personnel, ${ }^{8}$ whereas staff at the emergency units are generally at much higher risk of being a victim of physical violence. .,7 $^{2}$

Physical violence may result in not only serious physical injury but also mental health effects such as loss of morale and psychological morbidity among staff. ${ }^{4}$ One of the psychological sequelae is posttraumatic stress disorder, which can be disabling. To overcome the distressing nature of the experience, seeking support by confiding with friends, family, and colleagues are suggested..$^{10,11}$

In Nigeria, few surveys of physical assaults against mental health staff have been conducted. ${ }^{12,13}$ A study carried out in a psychiatric hospital in Lagos, South-South Nigeria, revealed that assault of mental health staff by patients is widespread. ${ }^{13}$ About half of the staff had experienced physical assault at least once within the period of their employment in the hospital; and $33.7 \%$ had been physically assaulted during the last 12 months before the study. Nurses $(82.3 \%)$ experienced more assault than doctors, and $44.3 \%$ of assaults occurred during routine assessment of patients. In all, $88 \%$ of physically assaulted staff sustained injuries requiring medical attention. The study, however, failed to investigate the means by which these victims are supported. 
The present study aimed to (1) assess the prevalence of physical violence against mental health professionals in a 12-month period and during their whole career; (2) identify factors, if any, associated with physical violence; (3) determine the type and physical/psychological consequences of physical violence against mental health professionals; and (4) investigate the sources of support for physically assaulted mental health professionals.

\section{Material and Methods}

This study was approved by the Ethics and Research Committee of the hospital. Written informed consent was obtained from each participant. This cross-sectional study was conducted at the Federal Neuropsychiatric Hospital in Benin, Edo, Nigeria. The hospital is a 270-bed facility that provides in-patient and out-patient care and emergency services to mentally ill persons across six states of Nigeria at two sites in Benin: an old site in the city and a new site in the outskirts of the city. The hospital is a walk-in and referral centre for persons with mental illness. The first point of contact is at the assessment unit which also doubles as the emergency unit. From there, patients are either admitted to the ward or given a clinic appointment. Mental illnesses commonly seen include externalising disorders in childhood, psychotic disorders, mood disorders, substance use disorders, and memory disorders in old age.

In accordance with previously reported studies of a similar nature, physical violence was defined as any act of physical aggression during which the patient deliberately and forcefully hits a caregiver with any part of his or her body or with an object, thereby inflicting pain and or injury to the victim. ${ }^{12,14}$ This includes the patient vigorously shaking, kicking, pushing around, biting, strangle-holding with resultant pain, reddening, indurations or bruising of the skin, or attempting to or actually raping the victim with evident damage to the clothing or apparel; threats or verbal aggression were not included. ${ }^{12,14}$

Mental health professionals (consultant psychiatrists, residents in psychiatry, psychiatric nurses, clinical psychologists, social workers, and occupational therapists) in the hospital were recruited to complete a questionnaire to record the socio-demographics (marital status, years of practice/experience, duration of practice in the hospital, job satisfaction) and history of physical violence, the context or circumstance in which it occurred, the type and the consequences, such as physical injuries, psychological distress, and means of support.

Statistical analysis was carried out using SPSS (Windows version 19; IBM Corp, Armonk [NY], US). Chi-squared test was used to test the association between categorical variables. All the variables except profession were dichotomized for easy comparison with previous studies. For example, the mean age of 39.7 was used to separate into older and younger age group. Profession was categorized into doctors (psychiatrists and trainees), nurses, and others (psychologist, social workers, and occupational therapists). The level of significance was set at $\mathrm{p} \leq 0.05$.

\section{Results}

Of 145 questionnaires distributed to the staff, 124 from 44 men and 80 women (mean age, $39.7 \pm 8.5$ years) were analysed, with a response rate of $85.5 \%$, and the rest were discarded owing to incomplete and/or inconsistent responses. Of the respondents, most $(61.3 \%)$ were nurses and least $(3.2 \%)$ were occupational therapists. The mean duration of employment was $8.2 \pm 7.6$ years.

$77(62.1 \%)$ staff had been assaulted during their whole career; $38(30.6 \%)$ of them were assaulted in the past 12 months (Table 1). Of the 77 staff assaulted, 48 (62.3\%) were nurses, $22(28.6 \%)$ were psychiatrists and trainees, and $7(9.1 \%)$ were other mental health professionals. The most common type of the most recent assault was pushing (32.9\%), followed by hitting $(26.4 \%)$; none reported sexual assault. Most assaults occurred in the wards (62.1\%), followed by the emergency unit $(25.8 \%)$ and clinics $(9.1 \%)$. The most common antecedent event to the most recent assault was calming an aggressive patient (44.1\%); $13.3 \%$ of assaults were unprovoked. $17(22.1 \%)$ of assaulted staff sustained injuries that required medical attention. Most injured persons received care from family and colleagues; few received support from relative/hospital management

Table 1. Frequency of type, location, and antecedent events to the attacks

\begin{tabular}{|lc|} 
& $\begin{array}{c}\text { No. }(\%) \text { of } \\
\text { respondents }\end{array}$ \\
Type of attack $(\mathrm{n}=91)$ & \\
Hitting & $24(26.4)$ \\
Shaking & $12(13.2)$ \\
Striking with an object & $7(7.7)$ \\
Kicking & $6(6.6)$ \\
Pushing & $30(32.9)$ \\
Attempted strangling & $6(6.6)$ \\
Biting & $4(4.4)$ \\
Attempted rape & 0 \\
Others (including spitting) & $2(2.2)$ \\
\hline Location (n = 66) & \\
Ward & $41(62.1)$ \\
Clinic & $6(9.1)$ \\
Emergency & $17(25.8)$ \\
Others (including office) & $2(3.0)$ \\
\hline Antecedent events (n =68) & \\
Attempting to calm patient & $30(44.1)$ \\
Restraining aggressive patient & $6(8.8)$ \\
Talking with patient & $11(16.2)$ \\
Giving instruction to the patient & $12(17.6)$ \\
Unprovoked & $9(13.3)$ \\
Others & 0 \\
\hline
\end{tabular}


Table 2.Sources of support and experience of posttraumatic stress disorder symptoms

\begin{tabular}{|lc|}
\hline Sources of support for injuries & $\begin{array}{c}\text { No. }(\%) \text { of } \\
\text { respondents }\end{array}$ \\
requiring medical attention (n=29) & \\
Hospital management & $2(6.9)$ \\
Family & $10(34.5)$ \\
Friends & $5(17.3)$ \\
Work colleagues & $7(24.1)$ \\
Patient's relatives & $1(3.4)$ \\
Co-religious members & - \\
Others (including staff) & $4(13.8)$ \\
\hline Experience of arousal, re-experiencing & \\
$\&$ avoidance symptoms (n=66) & \\
Never & $27(40.9)$ \\
Rarely & $11(16.7)$ \\
Sometimes & $24(36.4)$ \\
Frequently & $3(4.5)$ \\
Always & $1(1.5)$ \\
\hline
\end{tabular}

and none from religious group members; some received care from multiple sources (Table 2). 38 (57.6\%) of the assaulted staff 'never' or 'rarely' experienced posttraumatic stress disorder symptoms, whereas $24(36.4 \%)$ sometimes and 4 (6\%) frequently/always experienced such symptoms. 111 $(89.5 \%)$ participants considered assault can be prevented and $74(59.7 \%)$ considered it can be predicted.

Physical assault in the last 12 months was not associated with socio-demographics of the participants. However, physical assault in the whole career was associated with older age $(\mathrm{p}=0.04)$, longer years of practice $(\mathrm{p}=0.01)$, and job dissatisfaction $(\mathrm{p}=0.05)$ [Table 3].

\section{Discussion}

In our study, the whole-career prevalence of assault on mental health professionals by patients was $62.1 \%$, which is higher than $49.5 \%$ reported in a study by Ukpong et al. ${ }^{13}$ However, the 12-month prevalence of $30.6 \%$ is comparable to $33.7 \%$ reported in the same study. ${ }^{13}$ The higher wholecareer prevalence in our study may be because we surveyed the participants' lifetime experience beyond the current place of practice, whereas Ukpong et $\mathrm{al}^{13}$ surveyed the participants' career at the study hospital only. The high prevalence of assault on mental health professionals necessitates policy review regarding violence prevention, although in some cases violence is unavoidable.

In our study, assaults occurred more commonly on nurses $(62.3 \%)$ than on doctors $(28.6 \%)$. This finding is consistent with that reported in other studies. ${ }^{8,12,15}$ Among clinical staff, nurses followed by physicians experienced the highest rate of violence. ${ }^{15}$ Staff members who spend most time with patients are at greatest risk of experiencing an assault. ${ }^{5}$ Nurses have longer and closer contact with mentally ill patients than their co-workers and thus are at higher risk.

In our study, most assaults occurred in wards and emergency unit where patients are less stable, although the frequency in the wards outnumbered that at the emergency unit. This is not in keeping with observations made by other studies. ${ }^{6,7}$ However, other studies reported that assaults were more common at nursing station than emergency unit. ${ }^{12,13}$ It may be because emergency staff are more proficient in handling and avoiding assault, or patients spend less time in the emergency section thereby reducing the risk of assaults by patients. Physical assaults in clinics were uncommon because out-patients are typically more stable.

In our study, the most common event preceding physical violence was attempting to calm the patient, which is consistent with another study. Attempting to calm a patient indicates that aggression has already been brewing, and effort to cool off such agitation may fail. Assault is often the result when precautions are not taken. Restraining an aggressive patient was one of the least antecedent events to violence. Extra care and defensive handling of aggressive patients may avert physical assaults. However, because the restraining process is a physical one, assaults sustained during restraining an aggressive patient may not be considered as an assault and thus not reported.

Injuries sustained are usually minor and rarely severe. ${ }^{3,5}$ In our study, $22.1 \%$ of assaulted staff sustained physical injuries requiring medical attention, although the severity of injuries were not evaluated; severe injuries may not be rare. In addition, $42.4 \%$ 'sometimes' to 'always' experienced distressing mental symptoms (such as anxiety, bothersome memories of the experience, being hyper alert or vigilant, avoidance of the facility or the patient). In comparable studies of clinically significant posttraumatic stress disorder, the prevalence of mental distress in sufferers was $5 \%$ to $10 \% .^{16,17}$ The physical and psychological sequelae of physical assault include time off work and inefficient performance at work place.

Those with injury requiring medical attention mostly sought support from family members, friends, and colleagues. This is similar to reports from earlier studies of verbal aggression on nurses..$^{10,11}$ Family and friends are easily and readily accessible means of psychological and social support. In our study, few obtained support from the hospital management, although the type of support (emotional or financial) was not specified. In a correctional health service in New South Wales, Australia, counselling was provided to $92 \%$ of the victims of workplace violence. ${ }^{3}$ Our institution may need to develop policy on staff support following violent behaviour. This should start with reporting of all cases of physical violence to raise the awareness of the hospital management.

In our study, $89.5 \%$ of the respondents believed that violence could be prevented, and $59.7 \%$ believed that it could be predicted. It is worrisome that $40.3 \%$ believed that 
Table 3. Association of socio-demographic variables with violence in past 12 months and violence in the whole career

\begin{tabular}{|c|c|c|c|c|c|c|c|c|c|c|}
\hline & \multicolumn{5}{|c|}{ Violence in past 12 months } & \multicolumn{5}{|c|}{ Violence in whole career } \\
\hline & \multicolumn{3}{|c|}{ No. $(\%)$ of respondents } & \multirow{2}{*}{$\begin{array}{c}\text { Degrees } \\
\text { of } \\
\text { freedom }\end{array}$} & \multirow{2}{*}{$\begin{array}{c}P \\
\text { value }\end{array}$} & \multicolumn{3}{|c|}{ No. $(\%)$ of respondents } & \multirow{2}{*}{$\begin{array}{l}\text { Degrees } \\
\text { of } \\
\text { freedom }\end{array}$} & \multirow{2}{*}{$\begin{array}{c}P \\
\text { value }\end{array}$} \\
\hline & Yes & No & $\chi^{2}$ & & & Yes & No & $\chi^{2}$ & & \\
\hline Gender & & & 0.38 & 1 & 0.54 & & & 0.42 & 1 & 0.52 \\
\hline Male & $15(34.1)$ & $29(65.9)$ & & & & $29(65.9)$ & $15(34.1)$ & & & \\
\hline Female & $23(28.8)$ & $57(71.2)$ & & & & $48(60.0)$ & $32(40.0)$ & & & \\
\hline Age (years) & & & 1.91 & 1 & 0.17 & & & 4.33 & 1 & 0.04 \\
\hline $0-39$ & $17(25.4)$ & $50(74.6)$ & & & & $36(53.7)$ & $31(46.3)$ & & & \\
\hline$>40$ & $21(36.8)$ & $36(63.2)$ & & & & $41(71.9)$ & $16(28.1)$ & & & \\
\hline Religion & & & 1.86 & 1 & 0.17 & & & 1.41 & 1 & 0.24 \\
\hline Christian & $33(29.2)$ & $80(70.8)$ & & & & $69(61.1)$ & $44(38.9)$ & & & \\
\hline Islam / traditional & $5(50.0)$ & $5(50.0)$ & & & & $8(80.0)$ & $2(20.0)$ & & & \\
\hline Profession & & & 0.73 & 2 & 0.69 & & & 5.77 & 2 & 0.06 \\
\hline Doctors & $10(33.3)$ & $20(66.7)$ & & & & $22(73.3)$ & 8 (26.7) & & & \\
\hline Nurses & $24(31.6)$ & $52(68.4)$ & & & & 48 (63.2) & $28(36.8)$ & & & \\
\hline Others & $4(22.2)$ & $14(77.8)$ & & & & $7(38.9)$ & $11(61.1)$ & & & \\
\hline Ethnicity & & & 0.28 & 1 & 0.60 & & & 0.13 & 1 & 0.72 \\
\hline Bini / Isan & $24(32.4)$ & $50(67.6)$ & & & & $45(60.8)$ & $29(39.2)$ & & & \\
\hline Others & $14(28.0)$ & $36(72.0)$ & & & & $32(64.0)$ & $18(36.0)$ & & & \\
\hline Marital status & & & 0.00 & 1 & 0.99 & & & 0.95 & 1 & 0.33 \\
\hline Married & $30(30.6)$ & $68(69.4)$ & & & & $63(64.3)$ & $35(35.7)$ & & & \\
\hline $\begin{array}{l}\text { Single / separated / } \\
\text { widowed }\end{array}$ & $8(30.8)$ & $18(69.2)$ & & & & $14(53.8)$ & $12(46.2)$ & & & \\
\hline Years of practice & & & 3.38 & 1 & 0.07 & & & 6.67 & 1 & 0.01 \\
\hline $0-10$ & $20(25.0)$ & $60(75.0)$ & & & & $43(53.8)$ & $37(46.2)$ & & & \\
\hline$>10$ & $18(40.9)$ & $26(59.1)$ & & & & $34(77.3)$ & $10(22.7)$ & & & \\
\hline Job satisfaction & & & 3.43 & 1 & 0.06 & & & 3.82 & 1 & 0.05 \\
\hline $\begin{array}{l}\text { Very / moderately } \\
\text { satisfying }\end{array}$ & $28(27.2)$ & $75(72.8)$ & & & & $60(58.3)$ & $43(41.7)$ & & & \\
\hline Little / non-satisfying & $10(47.6)$ & $11(52.4)$ & & & & $17(81.0)$ & $4(19.0)$ & & & \\
\hline
\end{tabular}

violence could not be predicted; such belief may promote a relaxed attitude towards taking precautionary steps. Training on violence prevention should be emphasised on attitudinal change towards violence prediction.

In our study, experience of physical violence is associated with older age and longer years of practice, consistent with findings in other studies. ${ }^{13,18}$ In a study comparing two psychiatric hospitals in Nigeria in term of physical assaults by psychiatric patients against staff, staff of older age and longer years of employment had a higher rate of being assaulted. ${ }^{13}$

In our study, having been assaulted in the whole career was associated with poor job satisfaction, consistent with the finding reported in other studies. ${ }^{1,19-21}$ Physical violence may dampen the morale of staff, although the converse could also be argued; this may have negative effect on patient care and health service delivery. Nonetheless, the association was not reported with the 12-month violence prevalence. The disparity in time association may be due to the association between frequency of exposure to violence and lower job satisfaction..$^{21}$ It is more likely that staff would experience more violence in their whole career than in the past 12 months. However, there are other determinants of job satisfaction, including job stress, work setting, and rank. ${ }^{22}$ Hence, the association between exposure to violence and job satisfaction can be affected by these confounders.

There are limitations to our study. The cross-sectional study design to determine the prevalence of physical violence in the past is subjected to recall bias. In addition, many items in the questionnaire were omitted, perhaps because of poor recollection or partly or wholly avoidance of the events. An option of 'inability to remember' should have been included. Moreover, job satisfaction should have been properly investigated with a standardised scale. 


\section{Conclusions}

The present study found that, in a neuropsychiatric hospital in Nigeria, $62 \%$ of mental health professionals had experienced physical violence in their whole career, which was associated with older age, longer years of practice, and job dissatisfaction. The effect on physical injuries and psychological distress experienced thereafter may be substantial. Policy review and periodic training on violence prediction and prevention, as well as support for victims are recommended, with more attention given to nurses. The content of training should target changing attitudes towards violence prediction.

\section{Declaration}

All authors have no conflicts of interest to disclose.

\section{References}

1. Hesketh KL, Duncan SM, Estabrooks CA, Reimer MA, Giovannetti P, Hyndman K, et al. Workplace violence in Alberta and British Columbia hospitals. Health Policy 2003;63:311-21. Crossref

2. Kamchuchat C, Chongsuvivatwong V, Oncheunjit S, Yip TW, Sangthong R. Workplace violence directed at nursing staff at a general hospital in southern Thailand. J Occup Health 2008;50:201-7. Crossref

3. Cashmore AW, Indig D, Hampton SE, Hegney DG, Jalaludin BB. Workplace violence in a large correctional health Service in New South Wales, Australia: a retrospective review of incident management records. BMC Health Serv Res 2012;12:245. Crossref

4. Caldwell MF. Incidence of PTSD among staff victims of patient violence. Hosp Community Psychiatry 1992;43:838-9. Crossref

5. Erdos BZ, Hughes DH. Emergency psychiatry: a review of assaults by patients against staff at psychiatric emergency centers. Psychiatr Serv 2001;52:1175-7. Crossref

6. Kowalenko T, Walters BL, Khare RK, Compton S; Michigan College of Emergency Physicians Workplace Violence Task Force. Workplace violence: a survey of emergency physicians in the state of Michigan. Ann Emerg Med 2005;46:142-7. Crossref

7. Gerberich SG, Church TR, McGovern PM, Hansen H, Nachreiner NM, Geisser MS, et al. Risk factors for work-related assaults on nurses. Epidemiology 2005;16:704-9. Crossref
8. Zafar W, Siddiqui E, Ejaz K, Shehzad MU, Khan UR, Jamali S, et al. Health care personnel and workplace violence in the emergency departments of a volatile metropolis: results from Karachi, Pakistan. J Emerg Med 2013;45:761-72. Crossref

9. United States Department of Health and Human Services, National Institute of Mental Health. Epidemiologic Catchment Area Study, 1980-1985. Available from: http://doi.org/10.3886/ICPSR08993.v1. Accessed 12 January 2016. Crossref

10. Kwok RP, Law YK, Li KE, Ng YC, Cheung MH, Fung VK, et al. Prevalence of workplace violence against nurses in Hong Kong. Hong Kong Med J 2006;12:6-9.

11. Farrell GA, Bobrowski C, Bobrowski P. Scoping workplace aggression in nursing: findings from an Australian study. J Adv Nurs 2006;55:77887. Crossref

12. Ukpong DI, Abasiubong F, Ekpo AU, Udofia O, Owoeye OA. Violence against mental health staff in Nigeria: some lessons from two mental hospitals. Niger J Psychiatry 2011;9:14-7. Crossref

13. Ukpong DI, Owoeye O, Udofia O, Abasiubong F, Ukpong S. Violence against mental health staff: a survey in a Nigerian psychiatric hospital. Psychiatrist 2011;5:46-9. Crossref

14. Dhumad S, Wijeratne A, Treasaden I. Violence against psychiatrists by patients: survey in a London mental health trust. Psychiatr Bull 2007;31:371-4. Crossref

15. Privitera M, Weisman R, Cerulli C, Tu X, Groman A. Violence toward mental health staff and safety in the work environment. Occup Med (Lond) 2005;55:480-6. Crossref

16. Richter D, Berger K. Post-traumatic stress disorder following patient assaults among staff members of mental health hospitals: a prospective longitudinal study. BMC Psychiatry 2006;6:15. Crossref

17. Wykes T, Whittington R. Prevalence and predictors of early traumatic stress reactions in assaulted psychiatric nurses. J Forensic Psychiatry 1998;9:643-58. Crossref

18. Owen C, Tarantello C, Jones M, Tennant C. Violence and aggression in psychiatric units. Psychiatr Serv 1998;49:1452-7. Crossref

19. Wright NM, Dixon CA, Tompkins CN. Managing violence in primary care: an evidence-based approach. Br J Gen Pract 2003;53:557-62.

20. Wu D, Wang Y, Lam KF, Hesketh T. Health system reforms, violence against doctors and job satisfaction in the medical profession: a crosssectional survey in Zhejiang Province, Eastern China. BMJ Open 2014;4:e006431. Crossref

21. Shi J, Wang S, Zhou P, Shi L, Zhang Y, Bai F, et al. The frequency of patient-initiated violence and its psychological impact on physicians in China: a cross sectional study. PLoS One 2015;10:e0128394. Crossref

22. Leung SK, Spurgeon PC, Cheung HK. Job satisfaction and stress among ward-based and community-based psychiatric nurses. Hong Kong J Psychiatry 2007;17:45-54. 